\title{
Creutzfeldt-Jakob disease with mixed transcortical aphasia: insights into echolalia
}

\author{
S.E. McPherson ${ }^{1}$, J.D. Kuratani ${ }^{2}$, J.L. Cummings ${ }^{1,2,3}$, J. Shih ${ }^{4}$, P.S. Mischel ${ }^{5}$ and \\ H.V. Vinters ${ }^{5}$ \\ ${ }^{1}$ Department of Psychiatry and Biobehavioral Sciences and ${ }^{2}$ Department of Neurology, \\ UCLA, ${ }^{3}$ Behavioral Neuroscience Section, Psychiatry Service, West Los Angeles Veteran \\ Affairs Medical Center, ${ }^{4}$ Department of Neurology, University of New Mexico, and \\ ${ }^{5}$ Department of Pathology and Laboratory Medicine, UCLA School of Medicine, Los Angeles, \\ CA, USA \\ Correspondence to: S.E. McPherson, UCLA NPI, 760 Westwood Plaza, Los Angeles, CA 90024- \\ 1759 , USA
}

\begin{abstract}
Aphasia is a common manifestation of Creutzfeldt-Jakob disease (CJD), and investigation of the linguistic disorders of CJD patients may provide insights into the neurobiological mechanisms of language and aphasia. We report an autopsy-confirmed case of CJD in which the presenting symptom was change in language abilities. The patient ultimately evidenced mixed transcortical aphasia (MTA) with echolalia. Disruption of frontal-subcortical circuits with environmental dependency accounts for the symptoms in MTA, including intact repetition and echolalia. Observation in this patient and a review of the literature suggest that frontal-subcortical circuit dysfunction may contribute to the syndrome of echolalia. This hypothesis offers an alternative explanation to "isolation" of the speech area as the cause of MTA.
\end{abstract}

Keywords: Creutzfeldt-Jakob disease - Echolalia - Frontal-subcortical circuit - Mixed transcortical aphasia

\section{INTRODUCTION}

Creutzfeldt-Jakob Disease (CJD) is a uncommon, rapidly progressive dementing disorder caused by prions (Prusiner, 1987). The disease typically manifests with impairment of cognitive abilities, extrapyramidal dysfunction and myoclonus. Aphasia is frequent in CJD, usually appearing well into the course of the illness (Cummings and Benson, 1992). Few authors have described the specific characteristics of aphasia syndromes observed in CJD; Wernicke's aphasia (Mandell et al., 1989) and mixed transcortical aphasia (MTA; Drobny et al., 1991) have been observed.

We report a case of CJD in which language disturbance was among the first symptoms. As the illness progressed, the patient developed a classic MTA, characterized by non-fluent speech, with intact repetition, severely impaired comprehension and echolalia. The features of the language syndrome and the distribution of neurologic changes demonstrated by electroencephalogram (EEG), positron emission tomography (PET) and autopsy provide new insights into MTA and the neurologic basis of echolalia.

\section{CASE REPORT}

A 55 year old right-handed woman presented for evaluation of a rapidly progressing dementia. Symptoms began 6 weeks prior to her admission when the patient's husband noticed subtle changes in her personality, followed by an alteration in language 1 week later. Evaluation by a neurologist 3 weeks after onset of symptoms revealed an aphasia marked by paraphasic errors, both phonemic and semantic, and deficits in naming. Her spontaneous speech was disorganized and interrupted by frequent perseveration. The patient often repeated the word, "okay" and responded to questions by stating "um", "oh" and "huh" with varying intonation. In addition, when asked her age she correctly stated " 55 ", and then continued to respond " 55 " to all subsequent questions (e.g. "what is today's date?"). The patient was hospitalized and received acyclovir for possible herpes encephalitis despite normal results on two lumbar punctures. She was transferred for further evaluation.

On admission, a mental status examination revealed an alert, middle-aged woman with mildly disin- 
hibited behavior. She cooperated with the examiner but was distractible and appeared unaware of her deficits. Aphasia was the patient's most obvious abnormality. Her spontaneous speech output consisted of echolalia and stereotyped, spontaneous production of the word "okay". Her comprehension was severely impaired. She was able to follow one-step and sometimes two-step pointing commands and could respond appropriately to simple written words (e.g. "nose"). She could repeat three- and sometimes fourword phrases and could read single words and numbers aloud. She did not repeat non-meaningful phrases or nonsense words. She was able to write her name to dicatation on some occasions but not others. No other writing was possible. She was completely anomic, except for an occasional first response on a new set of objects. She was unable to name high or low frequency objects. For example, she correctly identified a cup, but was unable to name either a fork or a hammer. Prosody was intact and she could inflect her minimal output appropriately. She was able to count from 1 to 10 , recited the days of the week from Sunday through Thursday, and recited the alphabet from A through $\mathrm{J}$. The patient made grammatical corrections when asked to repeat sentences with erroneous derivational morphology (e.g. "She goed home" was changed to "She went home"), and there was evidence of the completion phenomenon (e.g. the phrase "Jack and Jill" was completed with "went up the hill" and "red, white and" was completed with "blue"). The presence of non-fluency of spontaneously generated speech, impoverished auditory comprehension, echolalia, selective perseveration of repetition, superiority of reading aloud over reading comprehension, retention of automatic speech, tendency to complete overlearned partial phrases, and ability to correct grammatical flaws in her repetition establish her linguistic syndrome as MTA. The patient exhibited variable attention and was easily distracted. Her behavior was marked by motoric, as well as verbal, perseveration. She could not calculate. She was able to copy two-dimensional but not three-dimensional figures. She perseverated when asked to copy multiple loops. Memory and other intellectual functions were untestable, although she knew her family and appeared to learn to recognize the hospital staff.

There was no history of recent illness, head trauma, or headaches different from the patient's usual tension and migraine headaches. There was no history of psychiatric disturbance before or during her illness. Surgical history included a hysterectomy, partial gastrectomy for peptic ulcer disease, and several cosmetic surgeries to her face and abdomen. She had multiple dental procedures spanning the period from 6 months to 6 weeks prior to her admission. The patient took estrogen and natural thyroid supplements for hypothyroidism and past Hashimoto's thyroiditis. Family history was significant for dementia of unknown cause in the patient's grandmother. General physical exam was unremarkable with normal vital signs. Neurological examination revealed no focal abnormalities. Her muscle tone, strength and coordination were normal, and there was no myoclonus. Muscle stretch reflexes were very brisk but symmetric and plantar responses were flexor. A pathologic grasp reflex was present bilaterally.

Tests of thyroid function, liver function, serum and cerebrospinal fluid (CSF) immunoglobulins and toxin assays were all within normal limits. Bacterial, fungal and viral CSF cultures were negative. Serum antibody titers for mycoplasma, lyme, viral encephalitis, and human immunodeficiency virus (HIV) were unrevealing. Chromosomal studies showed that the patient had neither of the two most common mutations of the PRNP gene at codons 178 and 200. She did have a 24-base deletion in the adjacent region of chromosome 20 between codons 51 and 91. Magnetic resonance imaging (MRI) of the brain was unremarkable. PET of the brain taken 3 weeks after onset revealed global hypometabolism, much more severe on the left than the right. The superior left frontal and parietal cortex demonstrated the most marked abnormalities. The head of the left caudate also had severe hypometabolism and there was moderate reduction of metabolism in the thalamus on the left (Fig. 1). The left primary visual cortex was hypometabolic. Near normal metabolic activity was present in the sensory-motor areas bilaterally and in the right primary visual cortex.

Three EEGs were taken during the course of the patient's illness. Results of the first recording, taken within a few weeks of onset, reported mild bilateral hemispheric slowing. The second recording, performed approximately 5 weeks after the onset of symptoms, revealed a posterior dominant rhythm of $8 \mathrm{~Hz}$ in the right occipital region. No comparable background activity was seen on the left. Photic stimulation elicited a driving response on the right but not the left. Throughout the EEG, sharply contoured $1.5-2 \mathrm{~Hz}$ periodic waves were present diffusely, but with higher amplitude and more rhythmicity anteriorly and over the left hemisphere. An EEG obtained 4 weeks later showed no consistent posterior background rhythm, and photic stimulation produced no discernible driving response. The record 


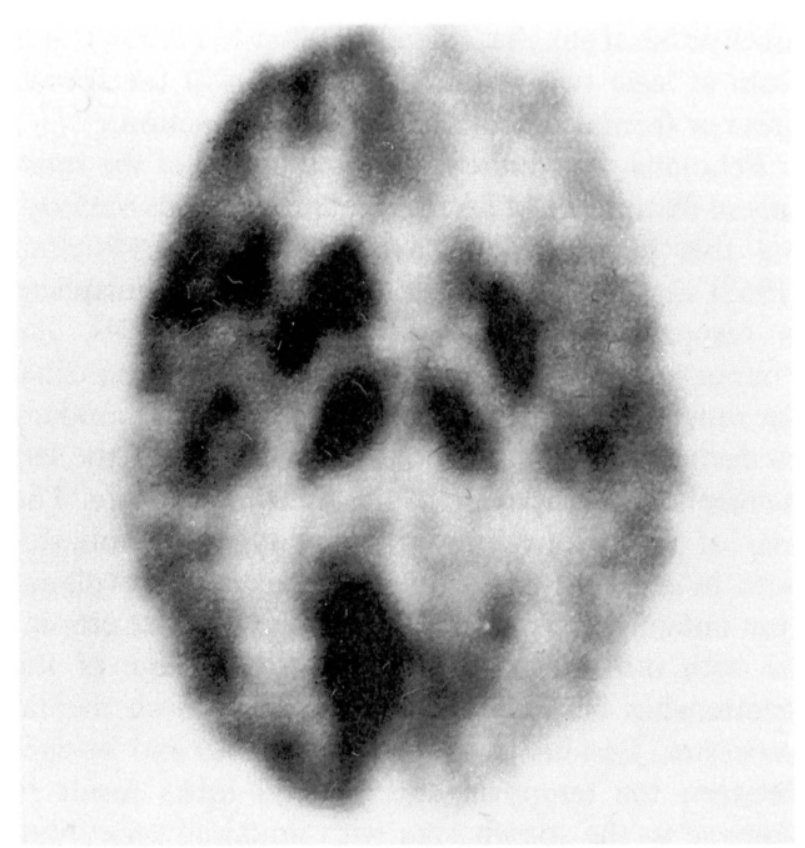

FIG. 1. PET of brain showing hypometabolism with moderate involvement of the thalamus on the left and marked abnormalities of the superior left frontal and parietal cortex. There is severe hypometabolism in the head of the left caudate and moderate reduction of metabolism in the thalamus on the left. agnosis of CJD was made. The patient returned for examination 9 weeks after the onset of symptoms. At that time, she exhibited no spontaneous speech, and echolalia, comprehension, repetition and automatic speech were absent. Aside from her mental status changes, her neurologic examination was unremarkable except for an increased startle response. Myoclonus was not present. The patient died at home 19 weeks after the onset of her symptoms.

Autopsy revealed severe spongiform encephalopathy with extensive spongy change and prominent neuronal loss and astrocytic gliosis involving the neocortex and deep central gray matter structures (Fig. 2). Extensive spongy change with vacuoles of irregular shape and size was seen both within the neuropil and in neurons. The neocortex, caudate, putamen, globus pallidus, thalamus and hypothalamus were all involved in varying degrees. There was minimal involvement of the cerebellum and selective sparing of the hippocampus. In the cerebellum, there was evidence of spongy change in the molecular layer, with preserved Purkinje and granule cells. No amyloid was detected. Pathologic findings confirmed the diagnosis of CJD.

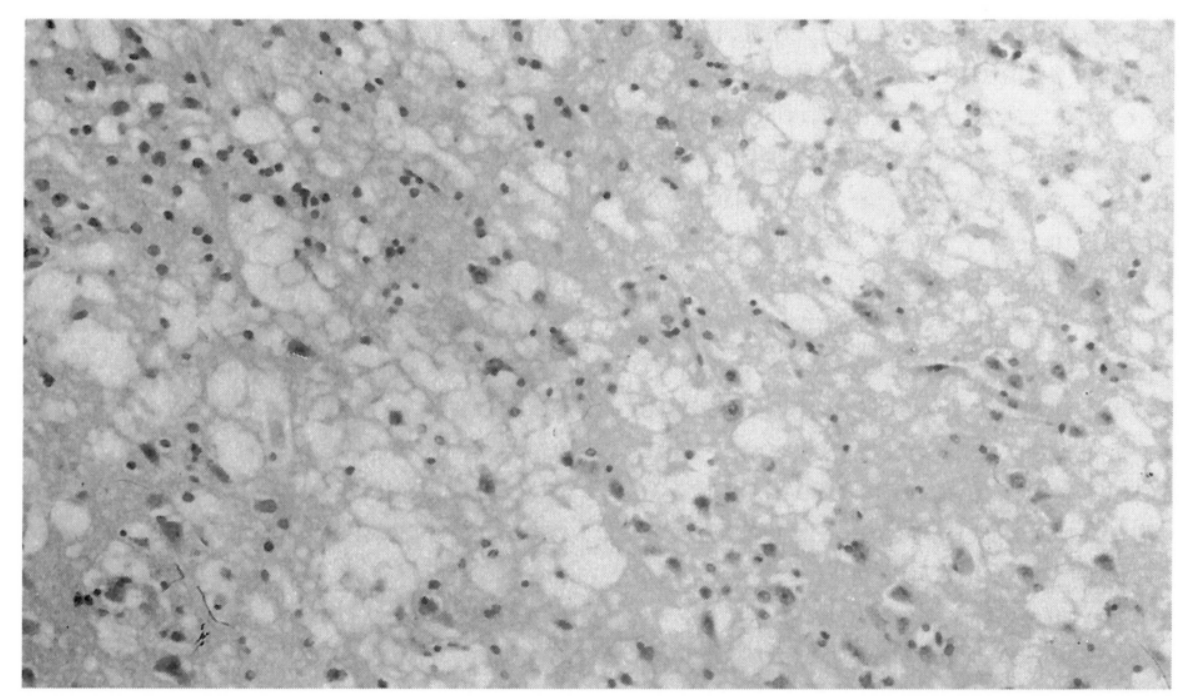

FIG. 2. Representative section of neocortex shows severe spongiform change, though scattered neurons remain intact. Many multi-loculated vacuoles are present. Hematoxylin and eosin, $\times 200$.)

was characterized by bilaterally synchronous $1.75 \mathrm{~Hz}$ sharply contoured periodic complexes with amplitudes up to $250 \mu \mathrm{V}$.

Following the initial evaluation, a presumptive di-

\section{DISCUSSION}

Language disturbance was the initial sign of cognitive deterioration in this patient. She eventually manifested MTA with non-fluent spontaneous speech, 
TABLE I. Language disorders as presenting symptom in $J C D$

\begin{tabular}{|c|c|c|}
\hline Author & First symptom(s) & Type of aphasia \\
\hline $\begin{array}{l}\text { Mandell et al. } \\
\text { (1989) ( } 1 \text { case) }\end{array}$ & Speech impairment & $\begin{array}{l}\text { Wernicke's } \\
\text { aphasia }\end{array}$ \\
\hline $\begin{array}{l}\text { Holthoff et al. } \\
\text { (1990) ( } 1 \text { case) }\end{array}$ & Speech difficulty & Mutism \\
\hline $\begin{array}{l}\text { Drobny et al. } \\
\text { (1991) (12 cases) }\end{array}$ & Mutism & $\operatorname{MTA}(n=3)$ \\
\hline $\begin{array}{l}\text { Gorman et al. } \\
\text { (1992) (1 case) }\end{array}$ & $\begin{array}{l}\text { Effortful speech; } \\
\text { echolalia }\end{array}$ & Mutism \\
\hline $\begin{array}{l}\text { Kao et al. (1993) } \\
\text { (1 case) }\end{array}$ & $\begin{array}{l}\text { Incomprehension of } \\
\text { speech, disorienta- } \\
\text { tion, behavioral } \\
\text { disturbance }\end{array}$ & $\begin{array}{l}\text { No further } \\
\text { description }\end{array}$ \\
\hline
\end{tabular}

MTA, mixed transcortical aphasia.

poor comprehension, anomia, intact repetition and echolalia. She had the completion phenomenon and made grammatical corrections in her repetitions. PET obtained at the time she evidenced MTA demonstrated cortical hypometabolism more severe in the left hemisphere and involving the parietal and frontal lobes, thalamus, and head of the caudate nucleus. These findings correlate with the predominantly left hemispheric deficits noted on her mental status examination and on her EEG. Autopsy confirmed the diagnosis of CJD.

Aphasia is often prominent in CJD, but it has rarely been observed as an initial symptom. A review of the english literature revealed only five case reports in which language disturbance was the presenting symptom (Table I). Details of the linguistic syndrome were provided in only two, one with Wernicke's aphasia (Mandell et al., 1989) and one with MTA (Drobny et al., 1991). In the three cases of MTA in CJD reported by Drobny and colleagues, no information was given regarding the specific linguistic deficits or course of illness. The present report adds to the literature concerning language disturbance in CJD by documenting a case in which a non-fluent aphasia, ultimately progressing to MTA, was the primary presenting symptom.

The diagnostic features of MTA are non-fluent spontaneous speech, preserved repetition with echolalia, and impaired comprehension (Goodglass and Kaplan, 1972). MTA, also known as "isolation aphasia", has generally been attributed to sparing or "isolation" of the peri-Sylvian language areas (Geschwind et al., 1968). A review of the english literature produced 18 cases of MTA with detailed clinical information (Table II). Of these, nine had isolation of the speech area, while seven had diffuse or multifocal lesions usually involving the frontal lobes or basal ganglia, suggesting that MTA can result from at least two processes-isolation of the speech areas or frontal subcortical circuit dysfunction.

Echolalia with intact repetition is one of the most salient features of MTA. Several mechanisms underlying this phenomenon have been posited. Nielsen (1962) suggested that while the dominant hemisphere is responsible for generative language skills, the "minor" or non-dominant hemisphere is responsible for repetition. Echolalia was posited to be secondary to destruction of the major language area of the left hemisphere and sparing of the right hemisphere. The loss of repetition skills in many types of aphasics with intact right brain function makes this explanation unlikely. Goldstein (1948) suggested that echolalia with intact repetition is due to damage of the relationship between speech and non-speech mental processes. Lesions in the temporal lobes and bridges between the temporal and parietal lobes result in damage to the speech area with impaired repetition. Lesions in the frontal lobe result in lack of impulse to speak, echolalia and repetition without comprehension or intention. This explanation is consistent with the distribution of lesions observed in several reported cases. Stengel (1964) posited that echolalia was not an automatic, compulsive, reflexive response, but a social response requiring a specific relationship between the patient and a speaking person. This was based on the observation that dysphasics only echo those comments directed toward him/her, but not other sounds such as barks, or the sounds from the radio. Geschwind and colleagues (1968) emphasized that peri-Sylvian structures of the left hemisphere must be spared for repetition to occur. Thus, Wernicke's, Broca's, and conduction-type aphasia all involve the peri-Sylvian region and impair repetition, while the transcortial aphasias (transcortical motor, transcortical sensory, MTA) feature intact repetition and the corresponding integrity of peri-Sylvian structures. The basis for the patient's spontaneous engagement in repetition in the form of echolalia was not addressed. Critchley (1970) proffered a psychopathological explanation suggesting that echolalia was secondary to extreme suggestability, identification with the interviewer, lack of insight, an impulse to maintain social contact through speech, and loss of linguistic inhibition.

Recent advances in understanding the relationship of the frontal cortex to subcortical structures and the clinical expression of frontal-subcortical circuit dysfunction facilitate the development of hypotheses regarding echolalia. There are five distinct prefrontalsubcortical circuits, each involving projections to the frontal cortex, striatum, globus pallidus/substantia 
TABLE II. Summary of cases reported with mixed transcortical aphasia

\begin{tabular}{|c|c|c|c|c|c|c|c|c|}
\hline Authors & Repetition & Echolalia & Completion & $\begin{array}{l}\text { Compre- } \\
\text { hension }\end{array}$ & $\begin{array}{l}\text { Spontaneous } \\
\text { speech }\end{array}$ & $\begin{array}{c}\text { Correct } \\
\text { agrammatic } \\
\text { sentences }\end{array}$ & Naming & Etiology \\
\hline $\begin{array}{l}\text { Geschwind et al. } \\
\text { (1968) }\end{array}$ & + & + & + & - & Non-fluent & NR & NR & $\begin{array}{l}\mathrm{CO} \\
\text { poisoning }\end{array}$ \\
\hline $\begin{array}{l}\text { Heilman et al. } \\
\text { (1976) }\end{array}$ & + & + & - & - & Non-fluent & $\begin{array}{l}\text { Inconsistent } \\
\text { performance }\end{array}$ & + & Unknown \\
\hline Ross (1980) & + & + & + & - & Non-fluent & + & - & $\begin{array}{l}\text { Left anteri- } \\
\text { or cerebral } \\
\text { artery } \\
\text { infarct }\end{array}$ \\
\hline $\begin{array}{l}\text { Pirozzolo et al. } \\
\text { (1981) }\end{array}$ & + & - & NR & - & Reduced & + & - & $\begin{array}{l}\text { Left parietal } \\
\text { hemorrhage }\end{array}$ \\
\hline Speedie et al. & + & NR & NR & - & Non-fluent & + & - & Infarct \\
\hline$(1984)(n=2)$ & + & NR & NR & - & Non-fluent & + & - & $\begin{array}{l}\text { Left parieto- } \\
\text { occipital } \\
\text { infarct }\end{array}$ \\
\hline $\begin{array}{l}\text { Bougousslavsky } \\
\text { et al. (1985) }\end{array}$ & + & - & NR & - & Reduced & NR & - & $\begin{array}{l}\text { Infarcts in } \\
\text { left frontal } \\
\text { lobe and } \\
\text { left parieto- } \\
\text { temporo-oc- } \\
\text { cipital } \\
\text { junction }\end{array}$ \\
\hline Bogousslavsky & + & + & & - & Reduced & NR & - & All four had \\
\hline \multirow[t]{3}{*}{$\begin{array}{l}\text { et al. (1988) } \\
(n=4)\end{array}$} & + & + & & - & $\begin{array}{l}\text { Isolated } \\
\text { words }\end{array}$ & NR & $\begin{array}{l}- \\
-\end{array}$ & $\begin{array}{l}\text { left internal } \\
\text { carotid }\end{array}$ \\
\hline & + & + & & - & Reduced & NR & - & artery \\
\hline & + & + & & - & Absent & NR & & occlusion \\
\hline $\begin{array}{l}\text { Mehler } \\
(1988)\end{array}$ & + & - & - & - & Absent & - & - & $\begin{array}{l}\text { Left cortical } \\
\text { atrophy }\end{array}$ \\
\hline $\begin{array}{l}\text { Trojano et al. } \\
\text { (1988) }\end{array}$ & + & + & + & - & $\begin{array}{l}\text { Impaired } \\
\text { speech } \\
\text { production }\end{array}$ & & NT & $\begin{array}{l}\text { Ischemic } \\
\text { areas in left } \\
\text { occipital } \\
\text { and right } \\
\text { periven- } \\
\text { tricular } \\
\text { areas }\end{array}$ \\
\hline \multirow[t]{2}{*}{$\begin{array}{l}\text { Papcsak et al. } \\
(1990) \\
(n=2)\end{array}$} & + & + & NR & - & Absent & NR & - & $\begin{array}{l}\text { Left frontal } \\
\text { infarct in- } \\
\text { volving an- } \\
\text { terior and } \\
\text { middle } \\
\text { cerebral } \\
\text { arteries }\end{array}$ \\
\hline & + & + & + & - & Absent & NR & - & $\begin{array}{l}\text { Left frontal } \\
\text { infarct in- } \\
\text { volving } \\
\text { middle cere- } \\
\text { bral artery }\end{array}$ \\
\hline \multirow[t]{2}{*}{$\begin{array}{l}\text { Grossi et al. } \\
(1991) \\
(n=2)\end{array}$} & + & + & + & - & Stereotypic & NR & NT & $\begin{array}{l}\text { Ischemic } \\
\text { areas in left } \\
\text { occipital } \\
\text { and right } \\
\text { periven- } \\
\text { tricular } \\
\text { areas }\end{array}$ \\
\hline & + & + & + & - & $\begin{array}{l}\text { Reduced/ } \\
\text { stereotypic }\end{array}$ & NR & NR & $\begin{array}{l}\text { Left fronto- } \\
\text { parieto- } \\
\text { temporal } \\
\text { infarct }\end{array}$ \\
\hline $\begin{array}{l}\text { Cappa et al. } \\
(1993)\end{array}$ & + & - & & - & Reduced & & - & $\begin{array}{l}\text { Lesion in } \\
\text { right periv- } \\
\text { entricular } \\
\text { white } \\
\text { matter and } \\
\text { lentricular }\end{array}$ \\
\hline
\end{tabular}

+, Present; -, absent; NR, not reported; NT not testable. 
TABLE III. Non-aphasic syndromes with echolalia

\section{Autism}

Catatonia

Fragile $X$ syndrome

Frontal lobe degenerations

General paresis

Gilles de la Tourette syndrome

Huntington's disease

Hyperekplexia

Latah

Miryochit

Neuroacanthocytosis

Post-encephalic Parkinson's disease

Schizophrenia

nigra, thalamus and back to frontal cortex. Three of these circuits mediate behavioral activities. Disruption of the dorsolateral prefrontal cortex results in executive dysfunction and deficits in motor programming; disruption of the orbitofrontal circuit results in irritability and disinhibition; and damage to the anterior cingulate circuit results in apathy and diminished initiative (Cummings, 1993). Orbitofrontal circuit damage and disinhibition may contribute to spontaneous echolalia. The patient cannot inhibit responses and "echoes" the examiner. Disruption of the dorsolateral circuit, which produces a decrease in verbal fluency, and of the medial frontal circuit which causes apathy, may be responsible for loss of generative linguistic abilities and poor output of spontaneous speech. Frontal lobe damage produces stimulus boundedness; the patient is unable to dissociate responses or shift attention from one stimulus to the next and becomes "bound" to the initial event. They exhibit stimulus-bound interactions with their environment and automatic imitation of behaviors (Lhermitte, 1986; Lhermitte et al., 1986). Echolalia may be a manifestation of stimulus boundedness, caused by the combined inability to shift away from any strong stimulus in the patient's perceptual field and an inability to inhibit responses. Stimulus boundedness and imitation behavior would result in the superiority of repetition over spontaneous speech and the occurrence of echolalia. The specific syndrome of MTA occurs when patients have injury to the left hemisphere, producing a linguistic deficit with poor comprehension, and simultaneously sustain damage to frontal-subcortical circuits resulting in environmental dependency and stimulus-bound behavior. They must have sufficient integrity of peri-Sylvian structures to allow perception and motor re-encoding of environmental stimuli. This explanation is consistent with the current patient's PET and EEG results with left parietal and frontal hypometabolism and predominantly left hemisphere dysrhythmias. Relative integ- rity of the right hemisphere may have contributed to her retained prosody and ability to inflect her output. CJD typically produces widespread hemispheric dysfunction and the tendency of the disorder to involve frontal and subcortical structures may account for the relatively large number of CJD patients reported to have MTA.

Observations in patients with focal lesions produced by stroke also support a role for frontal-subcortical circuit dysfunction in transcortical aphasia. Two patients with MTA secondary to left frontal lobe infarction have been described (Rapcsak et al., 1990). In both cases there was extensive damage to the dorsolateral prefrontal cortex extending inferiorly and medially to involve fiber tracts from orbitofrontal and medial frontal regions. Transcortical motor aphasia (TCMA) has many of the features of MTA except that comprehension is preserved. The lesions of TCMA spare posterior cortical regions mediating auditory-verbal decoding acitivities but involve frontal or subcortical structures. TCMA has been described in patients with lesions of left supplementary motor areas (Masdeu et al., 1978; Alexander and Schmitt, 1980), left frontal operculum (Stuss and Benson, 1986), frontal white matter deep to Broca's area (Naeser et al., 1982), and the basal ganglia (Naeser et al., 1982; Freedman et al., 1984).

Involvement of frontal-subcortical circuits may also explain the frequent occurrence of echolalia in non-aphasic syndromes (Table III). Echolalia has been observed in non-aphasic patients with frontal lobe degenerations, mental retardation (Stengel et al., 1947), autism (Rutter, 1966, 1985), Huntington's disease, neuroacanthocytosis, postencephalitic Parkinson's disease, catatonia (Ford, 1991), Gilles de la Tourette syndrome (Shapiro et al., 1978; Lees et al., 1984), hyperekplexia, latah, miryochit, schizophrenia, fragile X syndrome and general paresis (Lees, 1985). Notably, each of these disorders is associated with established or suspected pathology of the frontal lobe or member structures of the frontal-subcortical circuits. The occurrence of echolalia in these clinical syndromes supports the hypothesis that it is a sign of frontal-subcortical circuit dysfunction with environmental dependency and stimulus boundedness.

\section{Acknowledgements}

This project was supported by the Department of Veteran Affairs and a National Institute on Aging Alzheimer's Disease Core Center grant (AG10123).

\section{REFERENCES}

Alexander MP and Schmitt MA (1980) The aphasia syndrome of stroke in the left anterior cerebral artery territory. Archives of Neurology, 37, 97-100. 
Bogousslavsky J, Regli F and Assal G (1985) Isolation of speech area from focal brain ischemia. Stroke, 3, 441443.

Bogousslavsky J, Regli F and Assal G (1988) Acute transcortical mixed aphasia: A carotid occlusion syndrome with pial and watershed infarcts. Brain, 111, 631641.

Cappa SF, Perani D, Bressi S, Paulesu E, Franceschi M and Fazio (1993) Crossed aphasia: A PET follow-up study of two cases. Journal of Neurology, Neurosurgery and Psychiatry, 56, 665-671.

Critchley M (1970) Aphasiology and Other Aspects of Language. Edward Arnold, London.

Cummings JL (1993) Frontal subcortical circuits and human behavior. Archives of Neurology, 50, 873-880.

Cummings JL and Benson DF (1992) Dementia: A Clinical Approach, 2nd edn. Butterworth-Heinemann, Boston.

Drobny M, Krajnak V, Svalekove A and Pithova B (1991) Creutzfeldt-Jakob disease-Clinical picture analysis. European Journal of Epidemiology, 7, 511-516.

Ford RA (1991) Neurobehavioural correlates of abnormal repetitive behaviour. Behavioural Neurology, 4, 113-119.

Freedman MP, Alexander MP and Naeser MA (1984) Anatomic basis of transcortical motor aphasia. Neurology, 34, 409-417.

Geschwind N, Quadfasel FA and Segarra JM (1968) Isolation of the speech area. Neuropsychologia, 6, 327-340.

Goldstein K (1948) Language and Language Disturbances. Grune \& Stratton, New York.

Goodglass H and Kaplan E (1972) The Assessment of Aphasia and Other Disorders. Lea \& Febiger, Philadelphia.

Gorman DG, Benson DF, Vogel DG and Vinters HV (1992) Creutzfeldt-Jakob disease in a pathologist. Neurology, 42, 463.

Grossi D, Trojano L, Chiacchio L, Soricelli A, Mansi L, Postiglione A and Salvatore M (1991) Mixed transcortical aphasia: Clinical features and neuroanatomical correlates. European Neurology, 31, 204-211.

Heilman KM, Tucker DM and Valenstein E (1976) A case of mixed transcortical aphasia with intact naming. Brain, 99, 415-426.

Holthoff VA, Sandmann J, Pawlik G, Schroder R and Heiss WD (1990) Positron Emission Tomography in Creutzfeldt-Jakov disease. Archives of Neurology, 47, 1035-1038.

Kao CH, Wang SJ, Liao SH and Yeh SH (1993) Tc-99m HMPAO Brain SPECT findings in Creutzfeldt-Jakob disease. Clinical Nuclear Medicine, 18, 234-236.

Lees AJ (1985) Tics and Related Disorders. Churchill Livingston, New York.

Lees AJ, Robertson M, Trimble MR and Murray NMF (1984) A clinical study of Gilles de la Tourette syndrome in the United Kingdom. Journal of Neurology, Neurosurgery and Psychiatry, 47, 1-8.

Lhermitte F (1986) Human autonomy and the frontal lobes. Part II, Patient behavior in complex and social situations: The environmental dependency syndrome. Annals of Neurology, 19, 335-343.

Lhermitte F, Pillon B and Serdaru M (1986) Human autonomy and the frontal lobes. Part I, Imitation and utilization behavior: A neuropsychological study of 75 patients. Annals of Neurology, 19, 326-334.

Mandell AM, Alexander MP and Carpenter S (1989) Creutzfeldt-Jakob disease presenting as isolated aphasis. Neurology, 39, 55-58.

Masdeu JC, Schoene WC and Funkenstein H (1978) Aphasia following infarction of the left supplementary motor area: A clinicopathologic study. Neurology, 28, 12201223.

Mehler MF (1988) Mixed transcortical aphasia in nonfamilial dysphasic dementia. Cortex, 24, 545-554.

Naeser MA, Alexander MP, Helm-Estabrooks N, Levine HL, Laughlin SA and Geschwind N (1982) Aphasia with predominantly subcortical lesion sites. Archives of Neurology, 39, 2-14.

Nielsen JM (1962) Agnosia, Apraxia and Aphasia, 2nd edn. Hafner Publishing, New York.

Pirozzolo FJ, Keer KL, Obrzut JE, Morley GK, Haxby JV and Lundgren S (1981) Neurolinguistic analysis of the language abilities of a patient with a "double disconnection syndrome": A case of subangular alexia in the presence of mixed transcortical aphasia. Journal of Neurology, Neurosurgery and Psychiatry, 44, 152-155.

Prusiner SB (1987) Prions and neurodegenerative diseases. New England Journal of Medicine, 317, 1571-1581.

Rapcsak SZ, Krupp LB, Rubens AB and Reim J (1990) Mixed transcortical aphasia without anatomic isolation of the speech area. Stroke, 21, 953-956.

Ross E (1980) Left medial parietal lobe and receptive language functions: Mixed transcortical aphasia after left anterior cerebral artery infarction. Neurology, 30, 144-151.

Rutter M (1966) Behavioural and cognitive characteristics of a series of psychotic children. In: Early Childhood Autism-Clinical, Educational, and Social Aspects (Ed JK Wing), pp. 51-81. Pergamon Press, London.

Rutter M (1985) Infantile autism and other pervasive development disorders. In: Child and Adolescent PsychiatryModern Approaches, 2nd edn (Eds M Rutter and L Hersov), pp. 545-566. Blackwell, Oxford.

Shapiro AK, Shapiro ES, Brun RD and Sweet RD (1978) Gilles de la Tourette Syndrome. Raven Press, New York.

Speedie LJ, Coslett HB and Heilman KM (1984) Repetition of affective prosody in mixed transcortical aphasia. $\mathrm{Ar}$ chives of Neurology, 41, 268-270.

Stengel E (1964) Speech disorders and mental disorders. In: Disorders of Language (Eds AVS de Reuck and M O'Connor). Churchill, London.

Stengel E, Vienna MD and Edin LRCP (1947) A clinical and psychological study of echo-reactions. Journal of Mental Science, 93, 598-612.

Stuss DT and Benson DF (1986) The Frontal Lobe. Raven Press, New York.

Trojano L, Fragassi NA, Postiglione A and Grossi D (1988) Mixed transcortical aphasia on relative sparing of phonological short-term store in a case. Neuropsychologia, 26, 633-638.

(Received 7 June 1994; accepted as revised 19 October 1994) 


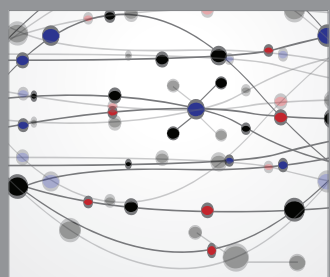

The Scientific World Journal
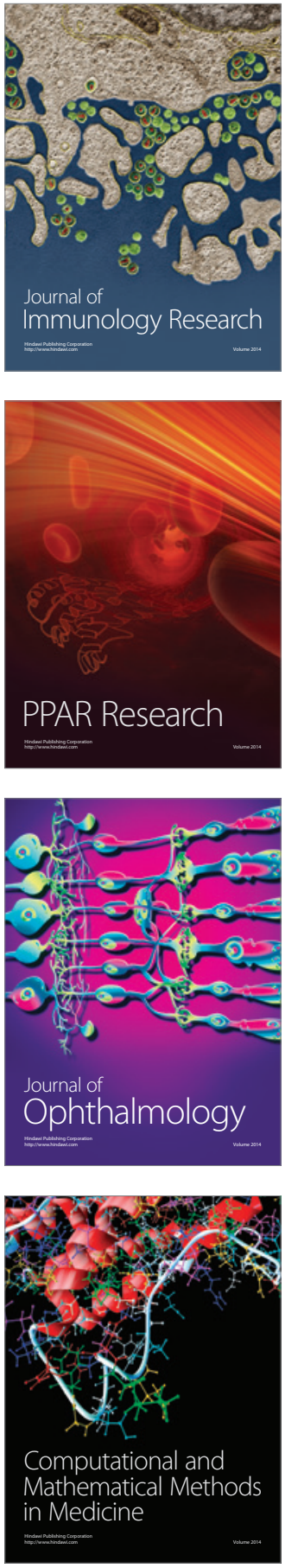

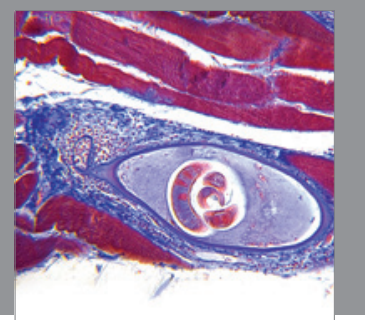

Gastroenterology

Research and Practice
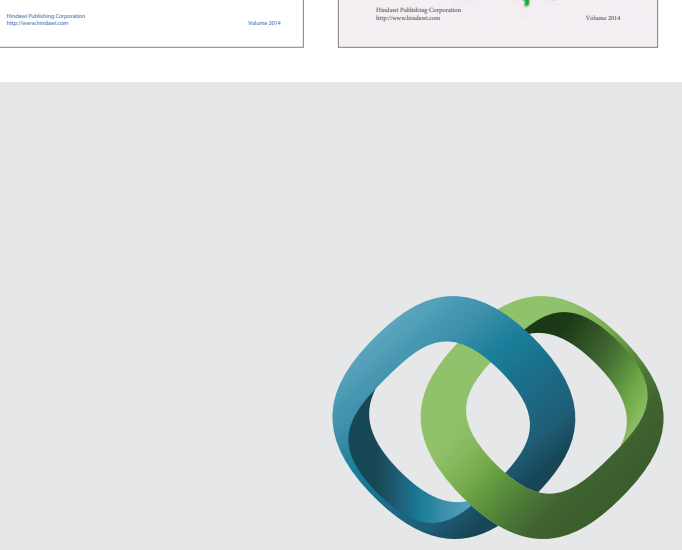

\section{Hindawi}

Submit your manuscripts at

http://www.hindawi.com
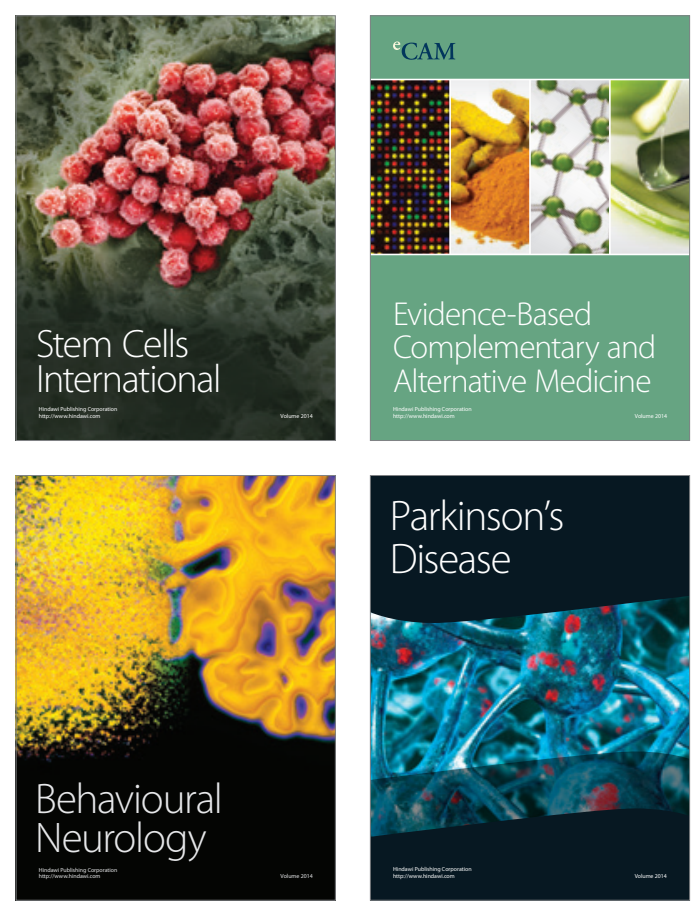

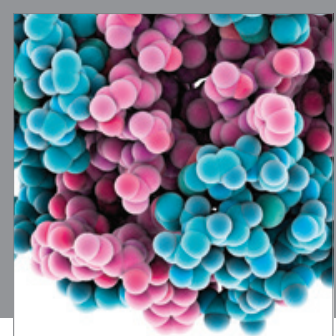

Journal of
Diabetes Research

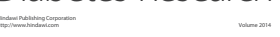

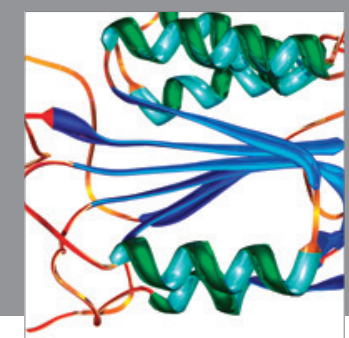

Disease Markers
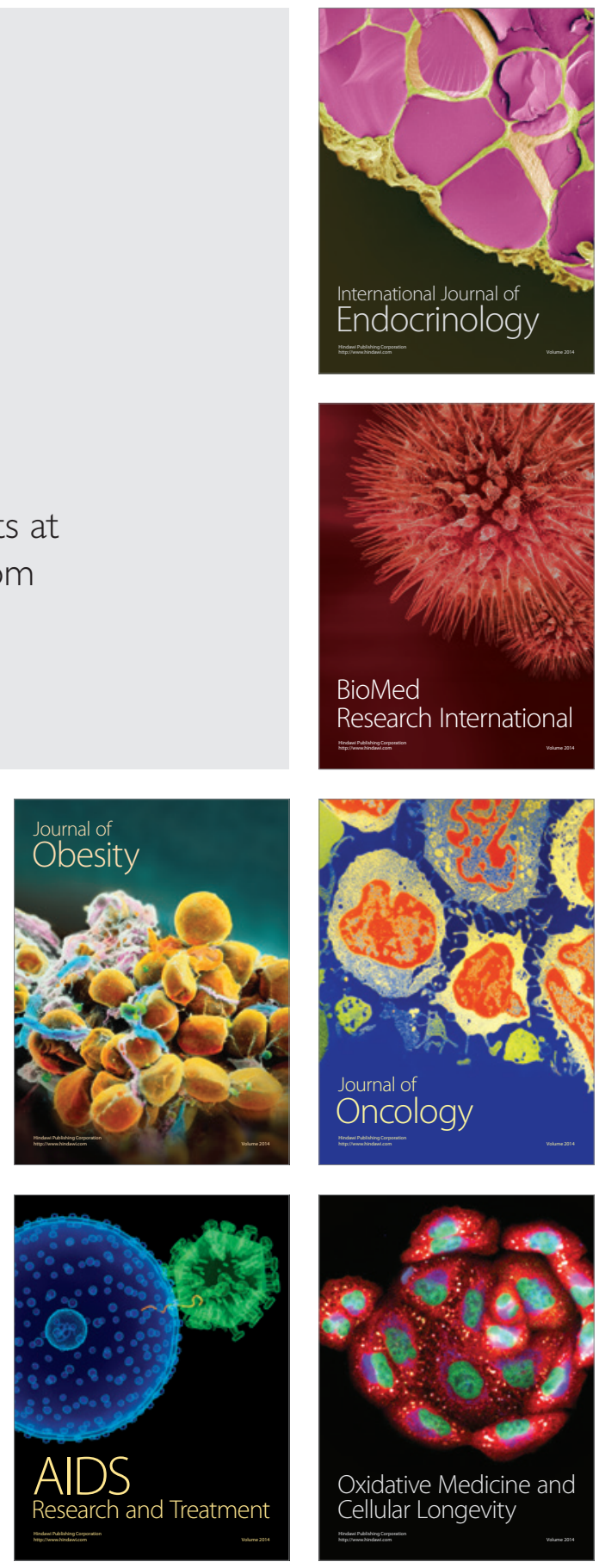